\title{
On the Management Mode of Colleges and Universities Under "Big Data Governance"
}

\author{
Xu Sha-Sha ${ }^{1,}$, Li Yuan $^{1}$, Yan Ting ${ }^{1}$, Zheng Kou-Quan ${ }^{1}$ \\ ${ }^{1}$ School of National University of Defence Technology, Communication \& Information College, Xi'an, Shaanxi 710061 \\ "Corresponding author. Email: 20376272@qq.com
}

\begin{abstract}
This paper analyses the function of "big data governance" from several aspects, such as improving the performance level of higher education governance. The combination of "big data" and "college management" brings the rich logical connotation of "big data college management mode". It will inevitably become the new requirements and new directions for the future development of higher education governance. Then, big data can promote the scientization of higher education governance decision-making, strengthen the cooperation of multiple subjects of higher education, and improve the social service ability of higher education This paper analyzes the function of "big data governance" from several aspects, such as improving the performance level of higher education governance.
\end{abstract}

Keywords: "big data governance", big data, data governance, college management

\section{Significance of "Big Data Governance"}

Big data is the product of information development to a certain stage. Comrade Xi Jinping pointed out that during the second collective study of the implementation of the national big data strategy in the Politburo of the CPC Central Committee, the development of big data change rapidly. We should take the time to plan, plan ahead, advance the layout, and strive to take the initiative to understand the current situation and trend of big data and its impact on economic and social development. We will analyze the achievements and problems of big data development in China which will promote the implementation of the national big data strategy, accelerate the improvement of digital infrastructure, promote the integration and open sharing of data resources, ensure data security, accelerate the construction of Digital China, and better serve the economic and social development of our country and the improvement of people's lives.

Nowadays, mobile payment, mobile payment and device sharing play an important role in people's life. Big data plays an important role in people's life. The big data can be used to form an interconnected and integrated social network space. In this epidemic, big data plays an important role. From material distribution to personnel management and control, big data can help the government analyze and provide decision-making conditions, such as respirators, masks and other medical resource equipment. It can also determine the movement track of each person and judge whether it is safe, suspected or confirmed!

\section{Problems Faced by "Big Data Governance" Institutions}

\subsection{Information island}

Data integrity is a great feature that big data can be used. In its data analysis, big data reflects the explicit and invisible relationship between data, that is, data mining, and then make the best use of data. But in reality, many of the data we get are "useless data", "dormant data", etc. the data collected by each department can't flow to each other and exist independently in their own databases, forming data islands and barriers, resulting in a large number of data resources waste. In Colleges and universities, each department has its own independent data and its own independent database, but the data between departments cannot be shared. When it is necessary to make statistics or update the data again, it will cause the data cannot be communicated and shared, and waste data resources and human resources.

\subsection{Each camp}

$\mathrm{n}$ the era of big data, the management system of modern colleges and universities needs to strengthen coordination, communication and flexible interaction among the multiple subjects involved. However, in the current system of complex organization and management level of colleges and universities, the transmission of information and data is not smooth, and the cycle of some data often determines the decision-making cycle. When the decision-making cycle is long, it will cause high administrative cost, large 
information loss and lack Lack of coordination and interaction. In addition, due to the different departments of colleges and universities, different data sources, different data formats, and other reasons, they are reluctant to communicate with other departments, unable to do accurate and evidence-based, unable to get good standardization, and the data is not closely related.

\section{3. "Big Data Governance" How to Solve the Problem of University Management}

\subsection{Building the concept of "big data governance"}

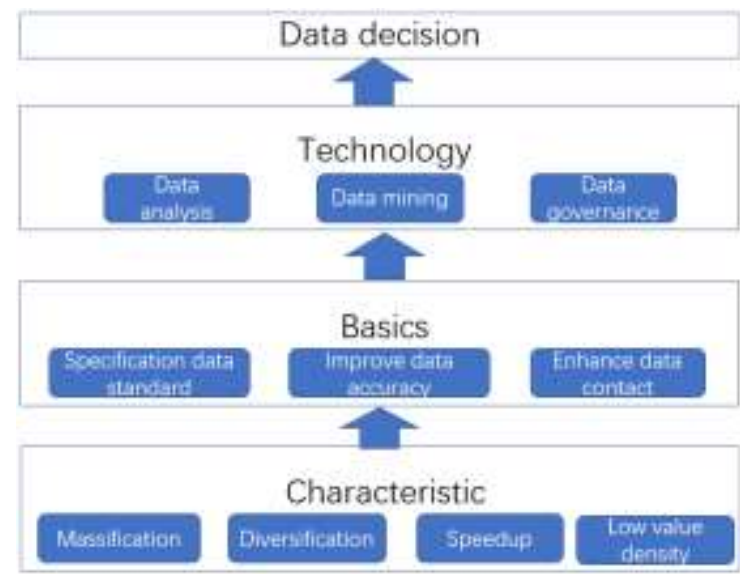

Figure 1 "big data governance" concept

As shown in Figure 1, we know that the large scale and growth of data in big data, the heterogeneity and diversity of data, and the large amount of irrelevant information make big data have the characteristics of large scale, diversification, speediness and low value density. These are just the basis of big data, which needs more data analysis at present, data mining, data governance, etc. Through data management and data innovation, data analysis in the governance of colleges and universities is realized, which provides the basis for data decision-making in the future. We should establish the idea of university governance with big data as the carrier, promote the idea of big data and the idea of relying on big data governance in an all-round way, especially promote the idea updating work for administrators of educational administrative institutions at all levels, and gradually abandon the traditional idea of "fragmented governance" through policy guidance, theoretical learning and practice promotion [1]. Set up the concept of "big data governance", pull through the data norms among departments, carry out data circulation, integrate data resources, and improve data utilization. From the previous single point data to multi-point data and data series transformation, to achieve the deep and effective integration between university governance and big data.

\subsection{Create "big data governance" model}

In the era of big data, the governance idea of "information is a kind of power" is more obvious, which marks the important transfer of governance power, and also requires breaking the past "center marginalization" governance structure and mode [2]. Strengthen the research and exploration of data analysis and application, adhere to the concept of "decision-making drives data, data determines design" closely around the teaching management decision-making, teaching evaluation, education supervision practice and teaching evaluation program research, as shown in Figure 2, adhere to the principle of "data collection focuses on system specification, data analysis focuses on combination mining, data application focuses on reliability and validity", and plan as a whole Research and carry out the collection, analysis and application of university management and teaching basic state data, so as to make the data between departments "live", data circulation and data sharing, and break the data barriers between departments. System planning, construction of data collection, analysis, application closely combined framework system. Find out the big data structure in line with the management of their own colleges and universities, establish a big data platform, reasonably use big data to govern colleges and universities, and truly realize the big data to provide data decision-making for colleges and universities.

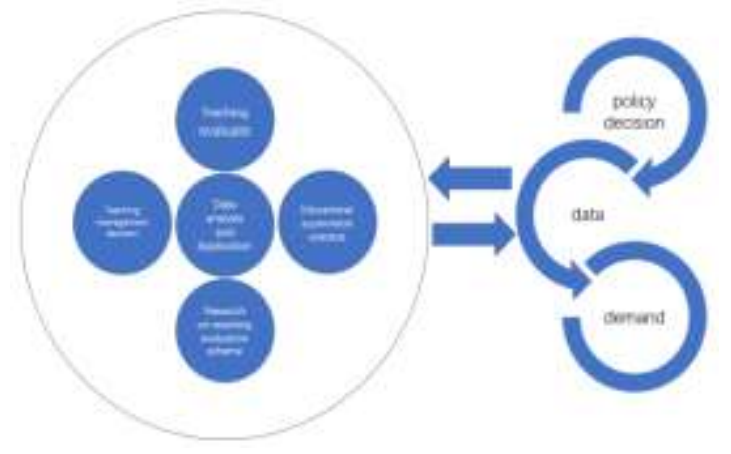

Figure 2 "big data governance" mode

\section{Development Direction of "Governance by Numbers"}

\subsection{Building the foundation of "big data governance"}

Big data has become an inevitable trend in the development of information technology. The "big data governance" based on big data is the new requirement of the reform of data governance mode in Colleges and universities. The "big data governance" of colleges and universities includes the following aspects: first, strengthen the investment and construction of big data infrastructure. Improve the understanding of big data strategic thinking, 
combine diversified data, use the "big data governance" mode, form the university data governance ecosystem, improve the data processing ability, data analysis ability, data mining ability, and finally lay a good foundation for data decision-making. Secondly, we should establish and improve the comprehensive big data system of university governance. For all kinds of data in the process of university governance, such as structural and non-structural data, numerical and non-numerical data, effective data mining, extensive collection, safe storage, management and in-depth research should be carried out. In particular, social resources in relevant professional fields should be gathered to form a big data force, forming good university governance data [2]. Finally, realize data sharing, promote data resource sharing and opening, break through barriers of different departments and systems, promote data circulation, form comprehensive big data resources, and lay a foundation for big data analysis and application.

\subsection{Optimize "big data governance" environment}

"Big data governance" provides comprehensive data analysis and trend prediction, which can well provide information resources for decision makers, and establish an efficient, convenient, safe and authoritative big data application database for colleges and universities. Through data coding and standardization, information between various systems of schools can be effectively exchanged, so that decision-makers, teachers, students of schools can All of them can use all kinds of data conveniently, improve the management level of the school, improve the working efficiency, and improve the core competitiveness of the school. College administrators should make full use of big data platform, deeply tap the value of big data, transform huge and complex big data information into warm, meticulous and humanistic services, make big data technology play a full role in campus management, teaching, scientific research, life, security and other aspects, so as to improve the core competitiveness of the school, and make campus management and information, and With the combination of modernization, we can promote the innovation and reform of campus management mode.

\subsection{Training "big data management" Talents}

Using big data to assist talent decision-making is a great change of talent decision-making. General secretary Xi Jinping pointed out that the purpose of "gathering talents" is to "use talents" if we want to "gather talents from all over the world". Under the "big data governance", the management of colleges and universities should pay more attention to personnel training, establish and improve the construction of big data platform, and provide effective technical support for the management of personnel file information in Colleges and universities, In order to better promote the optimal allocation of human resources in Colleges and universities, carry out more efficient and targeted education and training, and provide high-level and high-quality people for the society, we should master the dynamic of students' learning and life, better provide students with a broader learning space, and more accurately predict the development trend of human resources through data association, data analysis, effective cooperation between departments, and more accurate prediction Team. Therefore, only through the "big data governance" for the construction of information management of personnel files, can we make the quantitative analysis and scientific management of talent resources.

\section{CONCLUSION}

From "big data" combined with "university management", a "big data university management mode" with rich logical connotation has been formed. We start from the significance of research, discuss some problems faced and seek solutions, so as to better improve the quality of personnel training, and lay the foundation. "Big data university management mode" is bound to become a new requirement and new direction for the future development of higher education governance.

\section{ACKNOWLEDGMENT}

In the process of topic selection and research, this paper is supported and assisted by the National Social Science Foundation Project "Research on the mode and implementation path of" data-based governance "in military academies" (Project No.: 19cgl076). At the same time, I also want to thank the papers and monographs of the experts and scholars cited in this paper. Without the inspiration and help of the research results of these experts and scholars, I will not be able to complete the final writing of this paper.

\section{REFERENCES}

[1] Wang Yan, the path to the realization of "number based governance" in Higher Education [J]. Chinese adult education, 2018

[2] Liang Yong, vocational education "governance based on numbers": path and dilemma [J]. Continuing education research, 2016 (9) 
[3] Zhou Ping, challenges and Countermeasures of higher education management in the era of big data $[\mathrm{J}]$. Journal of Wuyi University, 2017 (10)

[4] Nan Xuguang, analysis and implementation path of "data-based governance" in Colleges and universities in the era of big data $[\mathrm{J}]$. China audio visual education, 2016, (08)
[5] He Wulin, research on formative evaluation of vocational education guided by "governance based on numbers", vocational education forum, 2019, (2)

[6] Sun Yulin. Application of big data in Vocational Education [J]. China higher education research, 2017 , (4)

[7] Huang Cuihua. Contradictions in modern vocational education system: representation, causes and Governance [J]. Vocational Education Forum, 2018, (2) 